\title{
DESAIN PEMBELAJARAN DESCHOOLING SOCIETY DAN RELEVANSINYA DENGAN KONSEP KAMPUS MERDEKA
}

\author{
Ita Nurmala Sari ${ }^{1}$ Khoirun Nisa ${ }^{2}$
} Sekolah Tinggi Agama Islam An-Nawawi Purworejo, Jawa Tengah
Email : itanurmalasari75@gmail.com ${ }^{1}$, irunicer@gmail.com ${ }^{2}$

\begin{tabular}{c|c|c}
\hline \multicolumn{3}{c}{ DOI: https:/ / doi.org/10.37758/jat.v3i1.206 } \\
\hline Received: Maret 2020 & Accepted: Juni 2020 & Published: Juni 2020 \\
\hline
\end{tabular}

\begin{abstract}
:
This research aims to uncover the design of deschooling society learning that was initiated by Ivan Illich and its relevance to the concept of an independent campus which became the Nadiem Makariem program. the concept of an independent or independent campus of learning, this is used to analyze primary ideas within the scope of the problem coupled with other relevant references, the approach in this research is a philosophical, historical factual approach used to study, understand and express related thoughts dischooling society and independent or independent learning campuses, while philosophical approaches are needed to examine, interpret, to be analyzed in depth to be associated with the two concepts above. The results of the study show that there is a intervention between deschooling society and the concept of an independent campus and produce learning designs that can be applied to educational institutions and tertiary institutions.
\end{abstract}

Key words : Learning Design, Deschooling Society, Merdeka Campus.

\begin{abstract}
Abstrak:
Penelitian ini bertujuan untuk mengungkap desain pembelajaran deschooling society yang digagas oleh Ivan Illich dan relevansinya dengan konsep kampus merdeka yang menjadi program Nadiem Makariem, Penelitiaan ini menggunakan metode penelitian kepustakaan (Library research) dengan mengacu pada metode deskriptif analisis kritis serta komparatif pada pemikirab Ivan Illich dan konsep Kampus merdeka atau merdeka belajar, hal ini digunakan untuk menganalisis gagasan primer dalam ruang lingkup permasalahan dengan ditambah dengan rujukan-rujukan lain yang relevan, pendekatan dalam penelitian ini adalah pendekatan faktual filosofis, historis yang digunakan untuk mengkaji, memahami dan mengungkap pemikiran-pemikiran terkait dischooling society dan kampus merdeka atau merdeka belajar, sedangkan pendekatan secara filosofis diperlukan untuk menelaah, memaknai untuk dapat dianalisis secara mendalam untuk dikaitkan dengan kedua konsep diatas. Hasil penelitian menunjukkan adanya relevensi antara deschooling society dengan konsep kampus merdeka serta menghasilkan desain pembelajaran yang dapat diterapkan pada lembaga pendidikan dan perguruan tinggi.
\end{abstract}

Kata Kunci : Desain Pembelajaran, Deschooling Society, Kampus Merdeka. 


\section{PENDAHULUAN}

Sejarah pendidikan di Indonesia saat ini masih mewariskan sebuah tradisi wajib tahu atau masih bersifat kaku tidak sesuai kemampuan siswa, hal tersebut dapat diamati dalam penerapan sistem hafal dimana guru memaksa siswa untuk mengetahui sebuah materi dengan cara harus tahu tidak harus paham. ini merupakan budaya menghilangkan sikap kritis dalam diri siswa yang menerima begitu saja suatu teori. siswa dituntut untuk berpartisipasi aktif dalam proses belajar, karena siswa hanya diisi dengan kata-kata oleh guru. sehingga siswa tidak bisa menerapkan apa yang mereka pelajari dan terima di sekolah. karena eksistensi mereka dalam sekolah atau kampus hanya sebagai pendengar yang pasif dari tindakan guru.

Dalam praktik pendidikan struktur sosial tidak pernah didiskusikan karena dianggap sebagai masalah yang perlu dipecahkan. Sebaliknya struktur sosial tersebut justru dibuat menjadi tidak jelas dengan berbagai cara yang mengakibatka siswa memiliki kesadaran salah. Dalam mengkritisi praktik pendidikan ini baik di tingkat dasar, menengah ataupun perguruan tinggi, menteri pendidikan nasional Indonesia merasa kwatir melihat kondisi pendidikan indonesia yang masih menerapkan praktik lama. Nadiem Makarim selaku Menteri Pendidikan melakukan terobosan baru dalam dunia pendidikan Indonesia yang selama ini beku dalam melihat realitas sosial yang dihadapi oleh bangsa Indonesia.

Nadiem membuat kebijakan di bidang pendidikan "Pendidikan di Indonesia memiliki konsep Merdeka Belajar, menjawab tantangan yang lebih mengedepankan kreativitas, rasa ingin tahu, tahan banting, empati, berfikir kritis, kemampuan menyelesaikan masalah, percaya diri, kerja sama, serta jiwa pembelajar". ${ }^{1}$ dalam lingkup perguruan tinggi nadiem mengeluarkan kebijakan dengan tajuk kampus merdeka, nadiem menyatakan “Kebijakan Kampus

\footnotetext{
${ }^{1}$ Moh. Muslim Syamsul Arifin, TANTANGAN IMPLEMENTASI KEBIJAKAN "MERDEKA BELAJAR, KAMPUS MERDEKA” PADA PERGURUAN TINGGI ISLAM SWASTA DI INDONESIA, AlIlmi: Jurnal Pendidikan Islam, vol. 3, 2020.
}

55 | At-Tarbiyat : Jurnal Pendidikan Islam, Vol. 03 No. 01 (2020) : 54-66 
Merdeka yang memberikan kesempatan kepada mahasiswa bertemu dan berpartisipasi dalam dunia kerja secara langsung dapat memperkaya wawasan dan pengalaman". Kebijakan kampus merdeka ini adalah perluasan otonomi, kemandirian, percepatan birokrasi dan peningkatan inovasi di perguruan tinggi. Melihat esensi kebijakan kampus merdeka tersebut maka, inovasi dan terobosan kreatif serta penguatan bidang ilmu menjadi modal yang sangat berharga dalam mengimplementasikan kampus merdeka. ${ }^{2}$

Pemerintah melalui Kementerian Pendidikan dan Kebudayaan memacu perguruan tinggi untuk mengembangkan diri sesuai tuntutan zaman yaitu menyiapkan sumber daya manusia yang adaptif di era Revolusi Industri 4.0. Hal tersebut merupakan salah satu dari empat pokok kebijakan kampus merdeka yang diluncurkan menteri pendidikan dan kebudayaan yang merupakan kelanjutan terobosan baru dari konsep merdeka belajar yang telah diluncurkan sebelumnya. Secara umum kebijakan keleluasaan perguruan tinggi ada 4 yaitu: kemudahan membuka program studi baru, perubahan sistem akreditasi kampus, kemudahan status kampus menjadi badan hukum, dan mahasiswa bisa magang 3 semester. $^{3}$

Nadiem makarim lebih lanjut menyatakan bahwa program studi di Indonesia tak lagi sesuai dengan kebutuhan dunia kerja. Program studi di Indonesia terlalu banyak teori, parahnya lagi teori tersebut tidak didampingi dengan praktiknya. Kurikulum di prodi-prodi di perguruan tinggi sifatnya sangat teoritis yang tidak link and match dengan kebutuhan di dalam dunia nyata. Prodi di Indonesia yang secara materi belum bisa bersaing dengan prodi tingkat dunia. Melalui program Kampus Merdeka harapannya dapat mempermudah perguruan tinggi membentuk prodi baru. Perguruan tinggi bisa bekerja sama dengan organisasi kelas dunia, badan nirlaba kelas dunia, BUMN

${ }^{2}$ Azmil Abidah et al., "The Impact of Covid-19 to Indonesian Education and Its Relation to the Philosophy of 'Merdeka Belajar,"' Studies in Philosophy of Science and Education 1, no. 1 (2020): 38-49, https://doi.org/10.46627/sipose.v1i1.9.

${ }^{3}$ M.Pd. Prof. Dr. Syafaruddin, M.Pd. Asrul, M.Si. Mesiono, INOVASI PENDIDIKAN (Suatu Analisis Terhadap Kebijakan Baru Pendidikan), Perdana Publising, vol. 53, 2012, https://doi.org/10.1017/CBO9781107415324.004.

56 | At-Tarbiyat : Jurnal Pendidikan Islam, Vol. 03 No. 01 (2020) : 54-66 
atau BUMD, serta universitas tingkat dunia. ${ }^{4}$

Sebagaimana yang dikatakan oleh Imanuel Kant bahwa manusia hanya dapat menjadi manusia karena pendidikan. "Man Can Become Man Through Education Only". Akan tetapi tujuan pendidikan tersebut, saat ini telah jauh dari harapan. Seperti yang terjadi di negara-negara berkembang, bahkan negaranegara maju sekalipun, semisal di Amerika Latin. Pendidikan hanya di jadikan sebagai komoditi yang di jajakan. Sedangkan guru adalah subyek aktif, dan anak didik adalah obyek pasif yang penurut. Pendidikan akhirnya bersifat negatif di mana guru memberikan informasi yang harus ditelan, serta wajib diingat dan dihafalkan.

Kemampuan pendidikan seperti ini, akan mengurangi atau menghapus daya kreasi dan kemampuan kritis pada siswa. Matinya sebuah kreasi dan kreativitas anak didik tersebut, akan membuatnya lamban untuk berkembang. Sehingga membuat siswa hanya sebagai penakut, pasif, serta jauh dari pemikiran kritis.Maka tidak heran, jika pendidikan semacam itu menuai banyak kritikan, sebut saja diantaranya adalah Ivan Illich. Walaupun masih banyak para pakar pendidikan lainnya yang jalan pikirannya berkaitan dengan kritik Ivan Illich seperti Paulo Freire , Carl Rogers, Abraham Maslow, B.F Skinner, Jerome Bruner, dan Malcom S. Knowles.Akan tetapi, makalah ini hanya akan mencoba mengkaji secara kritis, sedikit pemikiran dan gagasan Ivan Illich dalam dunia pendidikan.

Gagasan - gagasan Ivan Illich mengenai sekolah yang menurutnya justru membelenggu telah dituangkannnya dalam sebuah buku fenomenal berjudul "Deschooling Society". 5 buku yang ditulis Illich dalam rangka mengkritisi praktek kemapanan pendidikan yang selama beberapa tahun diselenggarakan oleh sekolah ini, dianggap sangat berbahaya oleh beberapa pihak. Ia dianggap telah menyadarkan masyarakat akan urgensi peninjauan ulang beberapa konsep yang selama ini dianggap mapan oleh sebagian besar masyarakat.

\footnotetext{
${ }^{4}$ Muhammad Yamin dan Syahrir, "Pembangunan Pendidikan Merdeka Belajar (Telaah Metode Pembelajaran)," Jurnal Ilmiah Mandala Education 6, no. 1 (2020): 126-36.

${ }^{5}$ Ivan Illich, Dischooling Society, 2004.
} 


\section{METODE PENELITIAN}

Penelitiaan ini menggunakan metode penelitian kepustakaan (Library research) ${ }^{6}$ dengan mengacu pada metode deskriptif analisis kritis serta komparatif pada pemikirab Ivan Illich dan konsep Kampus merdeka atau merdeka belajar, hal ini digunakan untuk menganalisis gagasan primer dalam ruang lingkup permasalahan dengan ditambah dengan rujukan-rujukan lain yang relevan, pendekatan dalam penelitian ini adalah pendekatan faktual filosofis, historis yang digunakan untuk mengkaji, memahami dan mengungkap pemikiran-pemikiran terkait dischooling society dan kampus merdeka atau merdeka belajar, sedangkan pendekatan secara filosofis diperlukan untuk menelaah, memaknai untuk dapat dianalisis secara mendalam untuk dikaitkan dengan kedua konsep diatas.

Dalam menganalisis data secara teknis, langkah yang digunakan adalah pengembangan dari metode analitis kritis. Teknis analisis yang digunakan dalam penelitian ini adalah: ${ }^{7}$

a) Menelaah seluruh data. Berbagai data atau konsep yang telah berhasil dikumpulkan melalui sumber bacaan dan diskusi dipahami secara saksama kemudian dideskripsikan, dianalisis, dikritisi dan diperbandingkan.

b) Hermeneutik. Teknik ini membantu penulis untuk memusatkan perhatian pada persoalan understanding of understanding terhadap teks. Metode ini digunakan untuk menyelami data dan konsep yang telah terkumpul agar menangkap atau memahami maknanya.

c) Komparasi. Metode ini digunakan penulis untuk menarik suatu kesimpulan dengan cara membandingkan pemikiran-pemikiran, ideide, metode-metode dan pengertian agar mengetahui persamaan dan perbedaan, kemudian menemukan relevansi implementasi dari konsep kedua pemikiran tersebut terhadap pendidikan.

\footnotetext{
${ }^{6}$ M Sesfao, "Perbandingan Pemikiran Pendidikan Paulo Freire Dengan Ajaran Tamansiswa Dalam Implementasi Merdeka Belajar,” Seminar Nasional Pendidikan 1, no. 1 (2020): 261-72, http://jurnal.ustjogja.ac.id/index.php/semnas2020/article/view/7554.

${ }^{7}$ Mestika Zed, Metode Penelitian Kepustakaan (Jakarta: Yayasan Obor Indonesia, 2008).
} 


\section{PEMBAHASAN}

\section{Desain Pembelajaran Deschooling Society}

Sekolah memiliki sebuah struktur, dimana struktur itu mengisyaratkan pesan bahwa individu tak bisa menyiapkan diri untuk hidup di masa dewasa dalam masyarakat tanpa melalui sekolah, apa yang tidak diajarkan di sekolah berarti kecil nilainya atau tak bernilai sedikitpun, dan apa yang dipelajari di luar sekolah tak layak diketahui. Ivan Illich menamakan struktur ini dengan Kurikulum Tersembunyidalam persekolahan, karena ia menjadi kerangka kerja sistem di mana segala perubahan atas kurikulum dibuat. Dan harus dimengerti dengan jelas, bahwa kurikulum tersembunyi menerjemahkan "belajar dari kegiatan" menjadi sebuah komoditas - dimana sekolah memonopoli pasar.Kurikulum tersembunyi adalah ritual yang bisa dianggap sebagai inisiasi resmi anak sebelum masuk ke masyarakat modern, ditetapkan secara intstitusional dalam sekolah. Tujuan ritual ini adalah bersembunyi dari mata para pesertanya, dalam pertentangan antara mitos tentang masyarakat egaliter dengan kenyataan kesadaran-kelas yang diabsahkannya, dari sinilah kemudian Ivan Illich mencoba untuk mendekonstuksi sekolah Disestablish School, akan tetapi dekonstruksi yang dilkukan oleh Illich ini guna membangun sebuah Convival Intitution (alternatif persekolahan). Karena Illich menganggap bahwa sekolah saat itu tidak dapat lagi di andalkan untuk membentuk kualitas anak didik. Akan tetapi bagaimanakah bangunan dari alternatif persekolahan tersebut? Itulah yang perlu kita pertanyakan. Bangunan dari alternatif persekolahan tersebut, sebagaimana yang dijelaskan oleh Ivan Illich adalah di bangun di atas style persekolahan yang sekarang. Sebagaimana yang ia tulis :

Universal education through schooling is not feasible. It would be more feasible if it were attempted by means of alternative institution built on the style of present schools.

Pendidikan Universal (alternatif persekolahan) yang dimaksud Illich tidaklah mustahil, dan itu akan menjadi mungkin jika alternatif persekolahan tersebut dibangun di atas model pendidikan sekarang.Illich menawarkan empat saluran khusus atau pertukaran kegiatan belajar yang bisa menampung semua unsure sumber daya yang dibutuhkan untuk kegiatan belajar yang menurutnya 
benar.Untuk menyebut saluran khusus tersebut, Illich cenderung menggunakan istilah"jaringan" (network). ${ }^{8}$

Dalam pandangan Illich, yang dibutuhkan oleh masyarakat sesungguhnya adalah jaringan baru, yang tersedia bagi umum dan dirancang untuk member kesempatan yang sama untuk belajar dan mengajar. Adapun empat jaringan pendidikan enurut Ivan Illich tersebut adalah. Pertama, jasa referensi pada objek-objek pendidikan yang memudahkan akses pada sesuatu atau proses yang digunakan untuk kegiatan belajar yang formal. Beberapa hal dapat dipakaiuntuk tujuan ini, karena disimpan di perpustakaan, agen penyewaan, laboratorium, dan ruang pertunjukkan seperti museum dan teater. ${ }^{9}$ Yang lainnya bisa digunakan sehari-hari di pabrik, bandar udara, atau sawah lading, tetapi tersedia bagi siswa untuk kegiatan magang atau kegiatan di luar jam sekolah. Kedua, pertukaran ketrampilan yang memungkinkan orang untuk mendaftarkan ketrampilan mereka, dalam kondisi seperti apa mereka mau menjadi model untuk orang lain yang ingin mempelajari ketrampilan ini, dan alamat dimana mereka bisa dihubungi. Ketiga, mencari teman sebaya yang cocok, yaitu suatu jarigan komunikasi yang memungkinkan orang menamparkan kegiatan belajar yang ingin mereka ikuti, dengan harapan menemukan pasangan yang cocok untuk kegiatan belajar mereka. Keempat, jasa referensi kepada pendidik pada umumnya yang bisa didaftar dalam sebuah buku petunjuk yang member alamat dan jati diri para professional, semi professional, dan ahli-ahli yang tidak terikat dengan suatu lembaga tertentu, dengan syarat untuk bisa memperoleh pelayanan mereka. Para pendidik ini bisa dipilih dengan melalui polling (mengumpulkan pendapat) atau dengan menanyai bekas-bekas klien mereka. ${ }^{10}$

Kurikulum tersembunyi mengajarkan kepada semua siswa bahwa

\footnotetext{
${ }^{8}$ Zulfatmi Zulfatmi, "Reformasi Sekolah (Studi Kritis Terhadap Pemikiran Ivan Illich)," Jurnal Ilmiah Didaktika 14, no. 1 (2013): 221-37, https://doi.org/10.22373/jid.v14i1.498.

${ }^{9}$ M Arfan Mu'ammar, "Gagasan Ivan Illich Tentang Pendidikan," Islamuna: Jurnal Pendidikan Islam 3, no. 1 (2016): 21.

${ }^{10}$ Abdul Rahman, "Urgensi Pedagogik dalam Pembelajaran dan Implikasinya dalam Pendidikan," BELAJEA: Jurnal Pendidikan Islam 3, no. 1 (2018): 83, https://doi.org/10.29240/bjpi.v3i1.358.
} 
ekonomi pengetahuan yang bernilai adalah hasil dari pengajaran yang professional, sehingga hak-hak sosial tergantung pada rangking yang telah dicapai dalam proses birokrasi. ${ }^{11}$ Kurikulum tersembunyi mengubah kurikulum yang eksplisit ke dalam sebuah komoditas dan menjadikannya kemahirannya sebagai bentuk yang paling aman untuk mendapat kekayaan.

Meskipun banyak kelemahan, sekolah tidak dapat dihapuskan begitu saja dengan segera, dalam situasi sekarang sekolah membentuk fungsi-fungsi negative penting tertentu. Kurikulum tersembunyi, secara tidak sadar diterima oleh para ahli pedagogi liberal, membuat frustasi arah liberal yang ia sadari, karena dalam kurikulum itu terdapat ketidak konsistenan yang melekat dengan mereka (para pedagogi liberal).

\section{Relevansi Dischooling Society Dengan Kampus Merdeka}

Menteri Pendidikan dan Kebudayaan Nadiem Makarim kembali membuat kebijakan baru yang diberi nama Merdeka Belajar: Kampus Merdeka, Kebijakan kampus merdeka ditujukan bagi lingkup pendidikan tinggi. Nadiem menyebutkan "ini tahap awal untuk melepas belenggu agar lebih mudah bergerak, ada beberapa matriks yang akan digunakan untuk membantu pendidikan tinggi mencapai targetnya".

konsep Merdeka Belajar-Kampus Merdeka dari Kemendikbud dapat diwujudkan ke dalam bentuk kegiatan pembelajaran, sesuai dengan Permendikbud Nomor 3 Tahun 2020 Pasal 15 ayat (1) meliputi: (1)pertukaran pelajar, (2) magang/praktik kerja, (3) asistensi mengajar di satuan pendidikan, (4) penelitian/riset, (5) proyek kemanusiaan, (6) kegiatan wirausaha,(7) studi/proyek independen, dan (8) membangun desa/kuliah kerja nyata tematik. $^{12}$

Mahasiswa diberikan kebebasan untuk mengambil ataupun tidak sks (Satuan Kredit Semester) di luar kampusnya sebanyak dua semester atau setara

\footnotetext{
${ }^{11}$ Tatas Transinata, "Integrasi Pendidikan Cinta Tanah Air dalam Kurikulum Tersembunyi Berbasis Karakter Kebangsaan,” Philantrophy Journal of Psychology 7, no. 1 (2017): 45-56.

${ }^{12}$ Sudaryanto Sudaryanto, Wahyu Widayati, dan Risza Amalia, "Konsep Merdeka Belajar-Kampus Merdeka dan Aplikasinya dalam Pendidikan Bahasa (dan Sastra) Indonesia," Kode: Jurnal Bahasa 9, no. 2 (2020): 78-93, https://doi.org/10.24114/kjb.v9i2.18379.
}

61 | At-Tarbiyat : Jurnal Pendidikan Islam, Vol. 03 No. 01 (2020) : 54-66 
dengan 40 sks. Ditambah, mahasiswa juga dapat mengambil sks di prodi lain di dalam kampusnya sebanyak satu semester dari total semester yang harus ditempuh. Namun, ini tidak berlaku untuk prodi kesehatan. ${ }^{13}$

Nadiem menilai saat ini bobot sks untuk kegiatan pembelajaran di luar kelas sangat kecil dan tidak mendorong mahasiswa untuk mencari pengalaman baru. Apalagi di banyak kampus, pertukaran pelajar atau praktik kerja justru menunda kelulusan mahasiswa. Perubahan pengertian mengenai sks. Jadi sks diartikan sebagai 'jam kegiatan', bukan lagi 'jam belajar'. Kegiatan di sini bisa berarti belajar di kelas, magang atau praktik kerja di industri atau organisasi, pertukaran pelajar, pengabdian masyarakat, wirausaha, riset, studi independen, ataupun kegiatan mengajar di daerah terpencil.

Jadi dari keempat poin tentang kampus merdeka yang diungkapkan Nadiem bertujuan membuat mahasiswa mampu berfikir kreatif mencoba berbagai hal tanpa takut salah atau dipersalahkan. ${ }^{14}$ Masa pandemi covid-19 ini makin mengukuhkan konsep merdeka belajar. Pandemi covid-19 membawa kita pada kondisi ketidak pastian. Idealnya model pendekatan free learning dirasa cocok diterapkan dalam menghadapi ketidakpastian. model free learning ialah merdeka berfikir, model berfikir seperti ini memerdekakan mahasiswa untuk coba-coba (trial and error). ${ }^{15}$ mahasiswa akan terus memperbaharui apa yang dicoba. Negara-negara pada dasarnya menggunakan model ini ketika mencoba menghadapi pandemi covid-19. Negara mengambil kebijakan yang sifatnya trial and error dan terus memperbaruinya sampai ditemukan kebijakan yang betulbetul pas, Itulah sebabnya negara-negara menerapkan kebijakan berbeda-beda bahkan berubah-ubah dalam mengatasi pandemi covid-19.

\footnotetext{
${ }^{13}$ Binar Kurnia Prahani et al., "The Concept of 'Kampus Merdeka' in Accordance with Freire's Critical Pedagogy," Studies in Philosophy of Science and Education 1, no. 1 (2020): 21-37, https://doi.org/10.46627/sipose.v1i1.8.

${ }^{14}$ H Suparto Wijoyo et al., "Hukum berada dalam selisik ragam dimensi kampus merdeka," Airlangga Development Journal 4, no. 1 (2020): 60-82.

${ }^{15}$ Siti Mustaghfiroh, "Konsep 'Merdeka Belajar' Perspektif Aliran Progresivisme John Dewey," Jurnal Studi Guru dan Pembelajaran 3, no. 1 SE-Articles (2020): 141-47, https://doi.org/10.30605/jsgp.3.1.2020.248.
}

62 | At-Tarbiyat : Jurnal Pendidikan Islam, Vol. 03 No. 01 (2020) : 54-66 
Pemikiran nadiem makarim tersebut sangat relevan sekali dengan ivan illich dengan konsep pembebasan kurikulum, kampus merdeka dengan konsep kuliah diluar kelas penulis anggap terdapat benah merah diantara keduanya, kuliah tidak selalu berada didalam kelas melainkan bisa berada dilingkungan pekerjaan (magang) asalkan dapat menambah pengetahuan dan pengalaman mahasiswa tersebut maka menurut konsep kampus merdeka hal demikian termasuk dalam sistem kredit semester (sks). Konsep kampus merdeka ini dianggap bebas karena mahasiswa bebas memilih mata kuliah di luar prodi yang dipilih.

Secara garis besar dapat kita tarik beberapa point konsep dischooling society Ivan Illich yang relevan dengan konsep kampus merdeka dalam dunia pendidikan tertuju pada sasaran-sasaran sebagai berikut :

1. Untuk membebaskan akses pada barang-barang dengan menghapus kontrol yang selama ini di pegang oleh orang atau lembaga atas nilainilai pendidikan mereka.

2. Untuk membebaskan usaha membagikan keterampilan dengan menjamin kebebasan mengajar atau mempraktekkan ketrampilan itu menurut permintaan.

3. Untuk membebaskan sumber-sumber daya yang kritis, dan kreatif yang dimiliki rakyat dengan mengembalikan kepada masing-masing orang, kemampuannya dalam mengumpulkan orang dan mengadakan pertemuan. Suatu kemampuan yang kini makin dimonopoli oleh lembaga-lembaga yang menganggap diri berbicara atas nama rakyat.

4. Untuk membebaskan individu dari kewajiban menggantungkan harapan-harapan pada jasa-jasa yang diberikan oleh profesi mapan manapun seperti sekolah, dengan memberikan kesempatan belajar dari pengalaman teman sebayanya dan mempercayakannya kepada guru, pembimbing, penasehat yang dipilihnya sendiri. Upaya membebaskan masyarakat dari kecenderungan menganggap sekolah sebagai satusatunya lembaga pendidikan mau tidak mau akan menghapus 
perbedaan ekonomi, pendidikan, dan politik yang menjadi tumpuan stabilitas tatanan dunia dan stabilitas banyak bangsa sekarang ini.

Dari poin-poin di atas dapat kita simpulkan bahwa Illich mencoba membebaskan masyarakat dari anggapannya tentang sekolah sebagai sarana satu-satunya untuk memperoleh pendidikan. Ilmu pengetahuan bagi Illich, tidak hanya dapat diperoleh dari sekolah, akan tetapi dapat diperoleh dari luar sekolah seperti lingkungan sekitar dan alam. Pada akhirnya, seorang siswa hanya bisa menuruti apa yang telah dijajakan oleh sekolah berupa ilmu pengetahuan, tanpa harus tahu dari mana dan bagimana ilmu pengetahuan tersebut.

\section{KESIMPULAN}

Dari pemaparan penulis diatas dapat kita simpulkan bahwa konsep dischooling society bauh pemikiran Illich mencoba membebaskan masyarakat dari anggapannya tentang sekolah sebagai sarana satu-satunya untuk memperoleh pendidikan. Ilmu pengetahuan bagi Illich, tidak hanya dapat diperoleh dari sekolah, akan tetapi dapat diperoleh dari luar sekolah seperti lingkungan sekitar dan alam. Pada akhirnya, seorang siswa hanya bisa menuruti apa yang telah dijajakan oleh sekolah berupa ilmu pengetahuan, tanpa harus tahu dari mana dan bagimana ilmu pengetahuan tersebut, konsep pembebasan kurikulum, kampus merdeka dengan konsep kuliah diluar kelas penulis anggap terdapat benah merah diantara keduanya, kuliah tidak selalu berada didalam kelas melainkan bisa berada dilingkungan pekerjaan (magang) asalkan dapat menambah pengetahuan dan pengalaman mahasiswa tersebut maka menurut konsep kampus merdeka hal demikian termasuk dalam sistem kredit semester (sks). Konsep kampus merdeka ini dianggap bebas karena mahasiswa bebas memilih mata kuliah di luar prodi yang dipilih. 


\section{DAFTAR PUSTAKA}

Abidah, Azmil, Hasan Nuurul Hidaayatullaah, Roy Martin Simamora, Daliana Fehabutar, dan Lely Mutakinati. "The Impact of Covid-19 to Indonesian Education and Its Relation to the Philosophy of 'Merdeka Belajar.'" Studies in Philosophy of Science and Education 1, no. 1 (2020): 38-49. https:/ / doi.org/10.46627/ sipose.v1i1.9.

Illich, Ivan. Dischooling Society, 2004.

Mu'ammar, M Arfan. “Gagasan Ivan Illich Tentang Pendidikan.” Islamuna: Jurnal Pendidikan Islam 3, no. 1 (2016): 21.

Mustaghfiroh, Siti. “Konsep 'Merdeka Belajar' Perspektif Aliran Progresivisme John Dewey." Jurnal Studi Guru dan Pembelajaran 3, no. 1 SE-Articles (2020): 141-47. https://doi.org/10.30605/jsgp.3.1.2020.248.

Prahani, Binar Kurnia, Utama Alan Deta, Mochammad Yasir, Sri Astutik, Paken Pandiangan, Sayidah Mahtari, dan Husni Mubarok. "The Concept of 'Kampus Merdeka' in Accordance with Freire's Critical Pedagogy." Studies in Philosophy of Science and Education 1, no. 1 (2020): 21-37. https://doi.org/10.46627/sipose.v1i1.8.

Prof. Dr. Syafaruddin, M.Pd. Asrul, M.Si. Mesiono, M.Pd. INOVASI PENDIDIKAN (Suatu Analisis Terhadap Kebijakan Baru Pendidikan). Perdana Publising. Vol. 53, 2012. https://doi.org/10.1017/CBO9781107415324.004.

Rahman, Abdul. "Urgensi Pedagogik dalam Pembelajaran dan Implikasinya dalam Pendidikan." BELAJEA: Jurnal Pendidikan Islam 3, no. 1 (2018): 83. https://doi.org/10.29240/bjpi.v3i1.358.

Sesfao, M. "Perbandingan Pemikiran Pendidikan Paulo Freire Dengan Ajaran Tamansiswa Dalam Implementasi Merdeka Belajar." Seminar Nasional $\begin{array}{lllll}\text { Pendidikan } 1, & \text { no. }\end{array}$ http://jurnal.ustjogja.ac.id/index.php/semnas2020/article/view/7554.

Sudaryanto, Sudaryanto, Wahyu Widayati, dan Risza Amalia. “Konsep Merdeka Belajar-Kampus Merdeka dan Aplikasinya dalam Pendidikan Bahasa (dan Sastra) Indonesia." Kode: Jurnal Bahasa 9, no. 2 (2020): 78-93. https:/ / doi.org/10.24114/kjb.v9i2.18379.

Syamsul Arifin, Moh. Muslim. TANTANGAN IMPLEMENTASI KEBIJAKAN "MERDEKA BELAJAR, KAMPUS MERDEKA" PADA PERGURUAN TINGGI ISLAM SWASTA DI INDONESIA. Al-Ilmi: Jurnal Pendidikan Islam. Vol. 3, 2020.

Transinata, Tatas. "Integrasi Pendidikan Cinta Tanah Air dalam Kurikulum Tersembunyi Berbasis Karakter Kebangsaan." Philantrophy Journal of

65 | At-Tarbiyat : Jurnal Pendidikan Islam, Vol. 03 No. 01 (2020) : 54-66 
Psychology 7, no. 1 (2017): 45-56.

Wijoyo, H Suparto, Sekolah Pascasarjana, Universitas Airlangga, Dosen Filsafat, Hukum Fakultas, dan A Introduction. "Hukum berada dalam selisik ragam dimensi kampus merdeka." Airlangga Development Journal 4, no. 1 (2020): 6082.

Yamin, Muhammad, dan Syahrir. "Pembangunan Pendidikan Merdeka Belajar (Telaah Metode Pembelajaran)." Jurnal Ilmiah Mandala Education 6, no. 1 (2020): 126-36.

Zed, Mestika. Metode Penelitian Kepustakaan. Jakarta: Yayasan Obor Indonesia, 2008.

Zulfatmi, Zulfatmi. "Reformasi Sekolah (Studi Kritis Terhadap Pemikiran Ivan Illich)." Jurnal Ilmiah Didaktika 14, no. 1 (2013): 221-37. https://doi.org/10.22373/jid.v14i1.498. 